\title{
Video as a Learner Scaffolding Tool
}

\author{
Marit Rismark and Astrid M. Sølvberg \\ Norwegian University of Science and Technology \\ Trondheim, Norway
}

\begin{abstract}
This article explores how videos support and scaffold students' study behaviour. To explore this, we have revisited data material from four of our previous studies. The constant-comparative method guided the analysis of in-depth interviews in the search for students' experiences of how videos support and scaffold study behaviour. The findings show that videos support and scaffold study behaviour along a timeline that includes study behaviour before, during and after lectures. The categories Scaffolded Preparation, Scaffolded Participation and Scaffolded Post-class Exploration inform us of how the length of the videos, their features and decisions about how and when students are to watch the videos are essential for how videos come to operate as a co-constructive force and scaffold for students' study behaviour.
\end{abstract}

Keywords: video; scaffolding; study behaviour; higher education; technological tools.

\section{Introduction and theoretical background}

Within a short span of time, videos have become a common part of how we communicate and share information. Likewise, the use of video is on the increase within higher education. This makes it necessary to explore how videos actually work as a pedagogical tool in the on-going efforts to improve teaching practice. It is also argued that the introduction of technological tools, such as videos, influences the teaching and learning process in substantial ways. Artefacts such as videos shape the actions of the people using them, and when technological devices act as mediators, they shape the behaviour and the social context of our existence (Verbeek, 2005). Thus, people not only act upon the inert, material environment, but the converse is also true. This materiality aspect of technology means that educational-technological tools may operate as coconstitutive components in educational practice (Tondeur, Herman, De Buck, \& Triquet, 2017; Tondeur, De Bruyne, Van Den Driessche, McKenney, \& Zandvliet, 2015). If videos are meant to scaffold student learning, university faculty members need insights into how videos influence the behaviour of students and the teaching context. In this article we will revisit data material from four 
previous studies involving use of video in higher education. The following research question is explored: How do videos scaffold students' study behaviour?

The exploration of this research question is based on analysis of data material from four studies within the disciplines of sociology (1), biology (2) engineering (3) and teacher education (4). These four studies have different focuses and priorities since it was each teacher and teacher group's actual practice that guided the process of developing research questions and deciding the design of each study. Pedagogical needs in the actual practices, such as flexible access to course lectures (Sølvberg \& Rismark, 2012), the need to encourage students to prepare for upcoming lectures (Rismark \& Sølvberg, 2007) or the need to produce an up-to-date curriculum (Sølvberg \& Rismark, 2016) have been points of departure for the research questions and the design of the studies. Inspired by the pedagogical needs in the educational practices, teachers' use of video was studied through the lenses of theories on educational practice and learning. In this way, references for decisions relating to why one should use video in the learning situation, which type of video to use and how to use it were grounded both in pedagogical reasoning about the actual teaching practice and theoretically-based reflections.

In all four studies the videos were intended to strengthen the existing practice according to specified pedagogical needs. The idea was not for the videos to change the existing practice. As such, the videos were incorporated into the existing practice. This line of action is found to be a quite common approach in innovative educational work involving the use of technology (Christensen, Horn \& Johnson, 2008).

\section{Videos and scaffolded learning}

With the remarkable growth in the use of video for pedagogical purposes in higher education comes the need to explore how video actually scaffolds students' study behaviour. Within educational practices, scaffolding is a classical concept, introduced by Vygotsky, and this contribution still set the stage for the idea of scaffolding that occurs in teaching and learning research now days. The concept describes the process where a competent person assists or helps somebody who is less competent to reach his or her zone of proximal development, ZPD (Vygotsky, 1978). As such, scaffolding enables a learner to solve a problem, carry out a task or achieve a goal that would be beyond his or her unassisted efforts (Wood, Bruner \& Ross, 1976, p.90). According to Vygotsky, social interaction is essential if the learner's cognitive and communicative capacity is to be expanded. In social interaction, the university teacher or other knowledgeable persons in the learning environment may function as scaffolding providers. This involves supporting the learner through feedback, questions, tips and reminders, as well as pushing and probing the learner to explore and encouraging reflection. In addition to the knowledgeable others in the learning environment, scaffolding providers may also be course material or technological tools such as videos. 
Videos have been used in educational settings for many decades. Initially, the use of video during early technologies gave students limited possibilities to interact while they watched videos, and there was little teacher and/or student control over content (Kearney \& Treagust, 2001). Today, a wide range of various types of videos is used to support various learning purposes in higher education and the research literature offers rich examples of how to use videos for learning purposes. Among the plethora of videos that may be used in educational activities are short videos, long videos, videos produced by teachers or by students, or pre-produced downloaded videos from the internet. In higher education, videos can be used to illustrate, present or demonstrate course content, and videos are used to support different learning designs, such as flipped learning, learning in the sky, Mooc and ordinary classroom teaching. Videos can have a scaffolding function in any learning design when providing learners with key information, offering structures that may reveal the subject's conceptual organization or providing hints about swift access to available learning resources. For example, videos can address concepts that are the most difficult and typically cannot be understood by students during their first encounter with them in the textbooks. Such scaffolding is usually provided in the early stages and at difficult points in student learning (Pan et al., 2012).

Videos are believed to have a nurturing value in educational practices. Ford, Burns, Mitch, and Gomez (2012) found that exposure to video is associated with improved study strategies and positive student perceptions of a course. Studies show that videos may also function well as a means to encourage learners. For example, when videos are short in length, have a personal and engaging feel, use a conversational language and relate directly to course assignments and assessment, they are engaging and interesting to students (Hibbert 2014; Guo, Kim \& Rubin, 2014). More lengthy videos, such as screencasts and video lectures may also be nurturing when successfully implemented (O'Callaghan, Neumann, Jones \& Creed, 2015). Studies show that such videos encourage learners, enhance learning and increase satisfaction and engagement (Choi \& Johnson, 2005, 2007; Koumi, 2006; Mackey \& Ho, 2008; Chen \& Wu, 2015). Morris and Chikwa (2014) found that although students' perceptions of screencasts are overwhelmingly positive, they suggested that screencasts should be kept short and summarize lectures or delve in-depth into complex concepts, but that they should not replace entire lectures. Another merit of a lengthy video is that the technology provides students with flexibility that allows them to learn in a more selfdirected fashion. For example, learners can regulate their own learning process by pausing, stopping, skipping and/or rewinding sections of a video.

In a discussion on shared online videos, Bonk (2011) argues that videos provide a context for learning and increase learner retention of information by extending learning beyond text to visual or episodic memory. Furthermore, it has been found that videos provide a shared experience for learners to discuss and reflect on concepts and ideas, and to provide advance organization for later class lectures, discussions and small group activities. Overall, videos seem to carry potentials that can assist learners in a positive manner. From this we argue that 
videos scaffold learners to solve a problem, carry out a task or achieve a goal that would be beyond their unassisted efforts.

\section{Methodology}

\subsection{Research context}

Since 2005 we have studied teachers' and students' use of digital technology in higher education and explored how university teachers use video in teaching and the ensuing student learning activities. In the present study, data material from four sub-studies is revisited to explore how videos that are introduced into the teaching practice support and scaffold students' study behaviour. The first is a study of a sociology course. All the lectures were video recorded in real time. Arrangements were made so that the students could either sit in on the lecture and view it on a screen in the classroom or access the video-recorded lecture outside the classroom on the university's learning management system (LMS). The second is a study of a biology course. Students used PCs or smart phones to access short videos that were made available through the university's LMS. The short videos (4-6 minutes) were designed to encourage students to prepare prior to the lectures. Similar short videos were designed and used in a third study of a teacher education programme. Students were introduced to videos in the university-based teaching where they were to design and use such videos during in-field training in primary and lower secondary schools. The fourth is a study of a post-graduate course for engineers. All the lectures were screencasted in real time and posted on the university's LMS. The complete catalogue of all the videos from the course functioned as the course curriculum as there was little written material for the course topics.

The research design involved close collaboration with university instructors teaching in the involved courses. The classic didactic triangle, described by Klafki (1997), functioned as a conceptual framework in all of the four substudies. Following this didactic triangle (see Figure 1), educational practice is perceived as involving the student, the teacher and some subject matter content. The triangle has three key axes in the didactic situation: the axis between teacher and student (communication axis), the axis between the teacher and the content (representation axis) and the axis between learner and content (experience axis). Along these three axes, we find three main relations: the relationship between teacher and student, between teacher and content and between student and content (ibid.). 


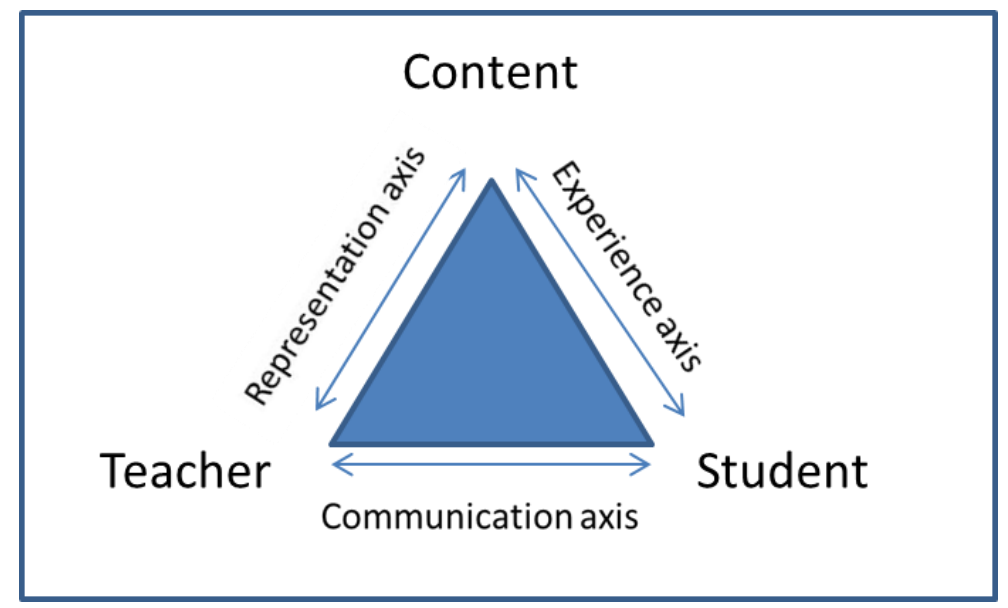

Figure 1: The didactic triangle

This conceptual framework functioned as a tool that guided the communication between researchers and research participants concerning features of the educational practice and the use of video during the periods of fieldwork.

\subsection{Participants and data collection}

The revisited data material consists of in-depth interviews with 65 university students in four different university courses. In-depth interviews permit exploration of a particular topic with a person who has a particular experience. Charmaz (2011) points out that a feature of intensive interviewing is that it elicits each participant's interpretation of his or her experience. Choosing and framing the interview questions so that they explore the interviewers' topic and fit the participants' experience was essential. This means that the questions have to be sufficiently general to cover a wide range of experiences and narrow enough to elaborate the participants' specific experience. Open-ended questions were designed to elicit the participants' views, experienced events and actions related to the videos. During the interviews, the interviewers (authors) paid attention to the respondents' language to bridge their experience with the research questions. This makes it possible to learn about the meanings of the terms the participants use and the specific properties they have, rather than making assumptions about what they mean.

The field procedure was as follows. Prior to the interviews, both interviewers sat in during course lectures so they could gather first-hand information about the organization of course activities, student behaviour and the use of video. The subsequent interviews were based on themes derived from this first-hand information from the classrooms. This enabled the interviewers to support the students in elaborating and clarifying multiple aspects of how videos support and scaffold student behaviour. The interviewers collaborated closely in planning the interviews and both were active contributors in the interview situation. The interviews lasted up to one hour and were recorded and thoroughly transcribed. 


\subsection{Procedures for data analysis}

The procedures for the data analysis started during the field work and continued after the data were collected. The research approach was inspired by grounded theory. This implies that we follow Charmazs' (2011) view on grounded theory methods as a set of principles and practices, not as instructions. The analysis used the constant comparative method (Glaser \& Strauss, 1967/1999), which involves making constant comparisons througout the analysis. The coding involved stopping and asking analytical questions of the data and comparing the data to find similarities and differences. The coding procedures also involved several phases (Charmaz \& Belgrave, 2012): initial or open coding, focused or selective coding and subsequently the development of sub-categories and the exploration of links between them based on insights into the experiences the categories represent. Initial coding or open coding involved the study of fragments of data, such as words, lines and segments, for their analytical importance. Focused or selective coding involved the selection of what seemed to be the most useful initial codes and then testing them against extensive data. This process involved comparison between data, and then comparison of data to codes. In this way the analysis involved moving back and forth between transcribed texts and theoretical assumptions based on the research question. Shifting between theory and data allowed us to capture multiple instances of how students experienced that the use of video supports the scaffolding of study behaviour. According to Strauss \& Corbin (1998), analysing data is about maintaining a certain degree of rigor. The researchers look for appropriate categories and make comparisons within a mass of unorganized raw data. During data analysis, we aspired to maintain rigor through work procedures involving mutual construction of meaning between co-researchers. This involved that we read and coded small extracts from the data individually before mutually developing preliminary categories.

\section{Findings}

The analysis reveals how videos scaffold students' study behaviour. The descriptions have been structured into three categories that together reflect a timeline that describes study behaviour before, during and after class. The overarching category "Scaffolded Study Behaviour" is described by the three sub-categories: Scaffolded Preparation, Scaffolded Participation, Scaffolded Postclass Activities.

\subsection{Scaffolded Preparation}

Scaffolded preparation describes how short videos (4-6 minutes) support students during preparation activities before lectures. The findings show that all the students prepared before lectures when they had access to such videos. A recurring trait in the data material is that the videos made the difference between preparing or not preparing at all: "I'm really bad at working on the material beforehand, so I think it's really good that we get these videos, if not I wouldn't have prepared...". As we see, the video represented a major shift in the study behaviour in terms of preparing for the lectures. The common 
procedure for preparation is described as following: "Usually preparations ahead of lectures mean browsing a large chapter, for example about proteins, and then realizing that I don't understand anything about the topic." Students also provide explanations about why they find it hard to prepare and how the videos make it easier to prepare:

"It's very difficult to know what to focus on, what to read. Because we have the videos it's easier to know what he (the university instructor) finds important. The videos show us what to read. If I have little time I don't have to read all of it. I now know what's important to read".

These insights about study behaviour prior to lectures provides a point of departure for a systematic look into the pedagogical features of the videos. The analysis revealed that there were four main features that scaffolded student preparations prior to the lectures. Firstly, the videos had a carefully chosen focal point (1). This means that the teacher selects a defined subject matter, introduces this briefly in the video and makes it clear which sections of the curriculum to study. A defined focus serves two purposes: it gives a shared focus of attention when the students and teacher meet in class, and it functions as a steppingstone for students when they explore the selected matter in any way they prefer. Secondly, the videos had questions and pointers (2). This means that the teacher encourages the students to investigate the subject matter further in any way they may prefer. The teacher underlines the need to search for further knowledge by introducing open-ended questions which provide some direction for student investigation. Moreover, the teacher uses pointers by suggesting that different paths of investigation will be relevant. Altogether, the questions and pointers serve the purpose of guiding student investigation. Thirdly, the video presents small puzzles or cases (3). This means that the teacher briefly introduces puzzles that may be solved in different ways. Furthermore, the teacher could tell a story followed by some questions that the students could look into. The form of the questions encouraged alternative solutions (e.g. 'what if?'). A fourth feature of the video is links from curriculum to students' everyday lives (4). This means that the teacher makes the defined subject matter relevant to students' everyday lives so that the video provides examples of how relevant subject knowledge relates to students' everyday lives.

The data analysis also shows that videos with the described features scaffold multiple ways of preparing prior to the lectures. Sometimes students watched the video ahead of lectures without further preparation. The video then functioned as a scaffold for students to gain surface subject knowledge about the upcoming topic. In such cases, the video in itself was the preparation, and the students did not use any other learning material. Opportunities for such preparations before the lectures were seen as a positive addition to the study situation:

"We're given small tasks, like finding a word or checking structures. And if I find the time I try to do it, but most of the time I forget about this and I watch the video right before the lecture." 
For this student the video is the difference between preparing or not preparing at all. Furthermore, the student expresses a general view, namely that such videos can provide support when it comes to gaining a general idea about the upcoming lecture when there is little time.

Sometimes students watched videos and followed up with additional preparation activities before the lectures. During these preparation activities they used a range of learning aids and information sources such as the main textbook, additional books, the internet, dictionaries and other reference works. The video then functions as a scaffold for students to gain detailed subject knowledge about the upcoming topic:

"...(in the video) he'll give some tasks, then I do the tasks, and then I'll read parts of the book and read the introductions to various chapters ... [...] ... and then occasionally I need to look up things in an encyclopaedia or something on the internet."

The Scaffolded Preparation category reveals that the videos were the difference between preparing and not preparing at all. They had a scaffolding function by providing learners with key information, clarifying challenging concepts and providing hints about available learning resources. We see here that the videos helped the students to establish a shared focus of attention during preparation activities. By working from a shared-preparation focus, the students then had surface subject knowledge or deeper subject knowledge prior to the lectures. The findings show that the short preparation videos strengthened the existing practice according to the teachers' ambitions about getting students to prepare ahead of lectures. Thus, we see that the videos scaffolded student behaviour according to the pedagogical purpose they were meant to serve.

\subsection{Scaffolded Participation}

Scaffolded Participation describes how the videos scaffold student behaviour during lectures. A recurring trait in the data material is that the videos scaffold student participation in different ways and that the length of the videos, their features and pedagogical considerations about how and when students should watch the videos are essential for how they come to scaffold student participation.

Up to this point, the analysis shows that short videos with a carefully chosen focal point, questions and pointers, encouragement to solve small puzzles and affordance of links from curriculum to students' everyday lives encourage preparation activities. With the help of the video-supported preparations, the students gained surface subject knowledge or deeper subject knowledge ahead of the lectures. When the students came to class, the teacher expected that the students and teacher would further investigate the subject issues together, and it was evident that the advance preparation activities provided some common ground for them during the lectures: "....when we prepare by watching videos we get to know what the professor is thinking about the topic and what he expects from us." The students found that the video provided information about the subject for the upcoming lecture. Furthermore, they found that the video also 
provided information about what was expected of them as participants in the upcoming lecture:

"I feel I miss out on something when I haven't watched the videos. The questions I may come to ask in class may seem to be out of place. ....I also see that other students who have not watched the video miss out on things, for example when the teacher asks 'what does this concept mean?"

According to the students, watching the videos made it easier to take the active role that the teacher expected during the lectures, for example by volunteering to explain concepts and answering simple curriculum questions. The students also stated that they missed out on something if they attended the lectures without having watched the videos. In this way, the video-supported preparations in advance of the lectures scaffolded in-class participation by providing cues that lowered the threshold for taking active roles during in-class investigation of subject issues and also supported students so they could take active roles in classroom communication in general.

Video lectures which the students could watch on a screen in the classroom while at the same time asking questions and interacting with the lecturer were meant to support real-time interaction with a number of lecturers who were offcampus. The students reported that they only attended the classroom session if they had matters to discuss or questions to ask, but there was hardly any communication during the classroom sessions. They felt that the technologies added stress to the learning situation and thus the students hardly communicated with the teacher during the lectures. Regularly, attendance to the lectures in the classroom was low. Instead, students organized learning activities outside the regular classroom. Instead, they gathered in their student office during lectures and viewed the lecture together in real time. Evidently, the video scaffolded the establishment of a new learning space, where the students gathered in the student office and at the same time watched the lecture together and individually in real time. The students explained why they established their own learning space:

"I have all my stuff in the office", "I can make a cup of coffee", "I'm more concentrated when I sit in front of my own computer, compared to when I sit in class. I use earphones so I only hear the speaker. It's easier to be involved in the situation in front of my PC as opposed to the classroom situation. When I sit in the office, I only watch the screen. In class, there are lots of other distractions."

These utterances show that the students were guided by their individual preferences for learning within their own, new learning space. They found it to be flexible according to place, pace, entry and exit, as opposed to joining the lecture in the classroom. Obviously, the new learning arrangements with the real-time lectures scaffolded student participation in other ways than intended.

Overall, the Scaffolded Participation category reveals how the videos influenced student behaviour during the lectures. Some videos had features that scaffolded 
in-class participation by providing cues for this. Other videos had features that scaffolded the establishment of new learning spaces outside the classroom.

\subsection{Scaffolded Post-class Curriculum Exploration}

This category describes how the videos scaffold students' study behaviour after lectures. All in all, the students were enthusiastic about having access to videorecorded lectures as they provided support when they needed to catch up on class lectures they had not attended. The videos also supported post-class curriculum exploration. An overall finding is that videos scaffold students when they are studying for upcoming exams. They found it helpful to go into the videos to re-listen to parts they felt they needed to elaborate on, repeat or understand better. Students also valued the opportunity to watch the videos to catch up on a lecture if they had not attended class. In this way, the videos supported flexible study behaviour. At the same time, this flexibility seemed to be demanding:

"We can always catch up at another time, but it requires extra initiative to get started. When you're attending the lectures, you're there during the whole session, but if you're catching up at a later point, you're also easily interrupted."

One general finding was that the students did not watch an entire video lecture, but rather bits and pieces, either to get a general orientation or to repeat particular sequences from it. As such, fragmented work was a recurring trait in the data. Generally, they watched for short periods of time and watched bits and sections of the video. When watching videos post-class, they were simultaneously engaged in other activities. For example, when they watched the videos at home, they were also engaged in domestic activities at the same time: "I've watched video-taped lectures on Sunday mornings and done the dishes at the same time". When post-graduate students who were able to study during working hours watched the videos, they were simultaneously engaged in atwork-related activities:

"I didn't listen through all these lectures, you know [...] so maybe I was sitting at my workplace with it on while I was working on something else, and then - And then - if there was something interesting, I'd stop a little, and listen a bit harder there [...] So I had it a bit in the background while I was doing other things."

The utterances above show that when studying post-class, the students have split attention, focusing on both curriculum issues and domestic or workplace activities.

Overall, the Scaffolded Post-class Exploration category describes that the videos scaffolded flexible study behaviour. At the same time, the flexibility involved affordances to watch bits and pieces of the video lectures. In this way the videos also scaffolded fragmented study behaviour involving split attention between curriculum activities and the life domains of home and work. 


\section{Discussion and conclusion}

This study set out to explore how videos that are introduced into teaching practice scaffold students' study behaviour. Inspired by grounded theory, the analysis of data material from four studies within the disciplines sociology, biology, engineering and teacher education revealed that videos scaffolded study behaviour along a timeline that includes study behaviour before, during and after lectures. The core category, Scaffolded Study Behaviour, is described according to three sub-categories: Scaffolded Preparation, Scaffolded Participation and Scaffolded Post-class Exploration.

The findings show that the videos assisted the learners in preparing, participating and carrying out post-class activities in ways that exceeded their "unassisted efforts" (Tharp \& Galimore, 2002; Wood et al., 1976). In this way, the videos clearly functioned as a scaffolding provider. The findings show that the length of the videos, their features and decisions about how and when the students are to watch the videos are essential for how videos come to scaffold students' study behaviour. Videos may scaffold students according to specified pedagogical needs in a teaching practice. For example, the findings show that watching short preparation videos scaffolded students in studying selected parts of the upcoming topic ahead of the lectures. In this way, the videos provided some common ground for the upcoming lectures. As Bonk (2011) points out, videos provide a shared experience for learners to discuss and reflect on concepts and ideas. However, in addition to being a shared experience, our findings show that the videos also provided additional shared information. The videos provided cues for participation that made it easier for the students to take active roles by volunteering to explain concepts and to answer questions. This implies that the videos may scaffold the students' study behaviour in unforeseen ways. This was also seen when we found that they scaffolded the students so they could establish new learning spaces outside the classroom. This meant that the students abandoned the organized learning space that was meant to support real-time interaction with a number of lecturers who were off-campus. As expected and in line with previous research (e.g. Chester, Buntine, Hammond \& Atkinson, 2011; Cooke et al., 2012; Sadik, 2015) the videos were also found to scaffold flexible study behaviour as the videos provided opportunities to learn at their own pace. This meant to review repeatedly or to skip material according to individual needs. At the same time, this flexibility seemed to be demanding. When watching videos post-class, the students were simultaneously engaged in other activities. As such, the videos scaffolded a fragmented study behaviour. This means that the use of video led to split attention between curriculum activities and other life domains, such as family life and work, that were drawn into the curriculum study activities.

The findings thus indicate that there is a close relationship between learner and technology in the researched educational practices. The videos are artefacts that shape the actions of the students using them. Bearing this in mind, our findings clearly demonstrate the materiality aspect of technology and how video operates as a co-constructive component (Tondeur et al., 2015; 2017) in the researched educational practices. Several authors argue that the materiality aspect of technology has been ignored or underestimated within education research 
(Barad, 2003; Fenwick, 2011; Lawn \& Grosvenor, 2005) when in fact it directs attention towards the importance of interaction between learner and technology. Kirschner and Erkens (2006) point out that this interaction promotes learners and technologies as "intellectual partners" in educational practice.

The study has some limitations. The results are based on a study of a limited number of students. Future studies should include larger groups. Such data would enable researchers to search for additional patterns in the data material. Furthermore, the combination of multiple sources of data collection, such as interviews and observations, would make it possible to find corroboration between the different data sources. These limitations notwithstanding, our findings provide new insights into how videos can scaffold students' study behaviour. These insights may be helpful for university faculty members when they plan to use videos for educational purposes. Further studies are needed to explore additional areas related to how videos may scaffold student learning in ways that bridge the gap between actual and potential performance.

\section{References}

Barad, K. (2003). Posthumanist Performativity: Toward an Understanding of How Matter Comes to Matter. Signs: Journal of Women in Culture and Society, 28(3), 801-831. doi:10.1086/345321

Bonk, C. J. (2011). YouTube anchors and enders: The use of shared online video content as a macro context for learning. Asia-Pacific Collaborative Education Journal, 7(1), 13-24. Retrieved from http://apcj.alcob.org/index.php

Charmaz, K. (2011). Constructing grounded theory. A practical guide through qualitative analysis. London: SAGE Publications.

Charmaz, K., \& Belgrave, L. L. (2012). Qualitative interviewing and grounded theory analysis. In J. F. Gubruium, J. A. Holstein, A. B. Marvasti \& K. D. McKinney (Eds.), The SAGE Handbook of interview research. The complexity of the craft (pp. 347362). USA: SAGE Publications, Inc. doi:10.4135/9781452218403.n25

Chester, A., Buntine, A., Hammond, K., \& Atkinson, L. (2011). Podcasting in education. Student attitudes, behaviour and self-efficacy. Educational Technology and Society, 14(2), 236-247. Retrieved from https://www.jets.net/ETS/issues7d36.html?id=51

Choi, H. J., \& Johnson, S. D. (2005). The effect of context-based video instruction on learning and motivation in online courses. The American Journal of Distance Education, 19(4), 215-227. doi:10.1207/s15389286ajde1904_3

Choi, H. J., \& Johnson, S. D. (2007). The effect of problem-based video instruction on learner satisfaction, comprehension and retention in college courses. British Journal of Educational Technology, 38(5), 885-895. doi:10.1111/j.14678535.2006.00676.x

Christensen, C. M., Horn, M. B., \& Johnson, C. W. (2008). Disrupting class. How disruptive innovation will change the way the world learns. New York: McGraw-Hill companies.

Cooke, M., Watson, B., Blacklock, E., Manash, M., Howard, M., Johnston, A., Tower, M., \& Murfield, J. (2012). Lecture capture: First year nurses' experiences of a webbased lecture technology. Australian Journal of Advanced Nursing, 29, 14-21. Retreived from http://www.ajan.com.au/ajan_29.3.html 
Fenwick, T. (2011). Reading educational reform with actor network theory: Fluid spaces, otherings, and ambivalences. Educational Philosophy and Theory, 43(sup1), 114134. doi:10.1111/j.1469-5812.2009.00609.x

Ford, M. B., Burns, C. E., Mitch, N., \& Gomez, M. M. (2012). The effectiveness of classroom capture technology. Active Learning in Higher Education, 13(3), 191-201. doi:10.1177/1469787412452982

Glaser, B. G., \& Strauss, A. L. (1967/1999). The discovery of grounded theory. Strategies for qualitative research. New York: Aldine de Gruyter.

Guo, P. J., Kim, J., \& Rubin, R. (2014). How video production affects student engagement: An empirical study of MOOC videos. In Proceedings of the first ACM conference on Learning@ Scale conference, L@S'14, 41-50. doi:10.1145/2556325.2566239

Hibbert, M. C. (2014). What makes an online instructional video compelling? Educause Review Online. Columbia University Academic Commons, https://doi.org/10.7916/D8ST7NHP

Kearney, M., \& Treagust, D. F. (2001). Constructivism as a referent in the design and development of a computer program using interactive digital video to enhance learning in physics. Australian Journal of Educational Technology, 17(1), 64-79. doi:10.14742/ajet.1773

Klafki, W. (1997). Kritisk-konstruktiv didaktik [Critical-constructive didactics]. In M. Uljens (Ed.), Didaktik-teori-reflektion och praktik [Didactics-theory-reflection and practice] (pp. 215-228). Lund: Studentlitteratur.

Kirschner, P., \& Erkens, G. (2006). Cognitive tools and mindtools for collaborative learning. Journal of Educational Computing Research, 35(2), 199-209. doi:10.2190/r783-230m-0052-g843

Koumi, J. (2006). Designing video and multimedia for open and flexible learning. doi:10.4324/9780203966280

Lawn, M., \& Grosvenor, I. (Eds.). (2005). Materialities of schooling: Design, technology, objects, routines. doi:10.15730/books.12

Mackey, T. P., \& Ho, J. (2008). Exploring the relationships between web usability and students' perceived learning in web-based multimedia (WBMM) tutorials. Computers \& Education, 50(1), 386-409. doi:10.1016/j.compedu.2006.08.006

O'Callaghan, F. V., Neumann, D. L., Jones, L., \& Creed, P. A. (2015). The use of lecture recordings in higher education: A review of institutional, student, and lecturer issues. Education and Information Technologies, 22(1), 399-415. doi:10.1007/s10639-015-9451-z

Pan, G., Sen, S., Starrett, D. A., Bonk, C. J., Rodgers, M. L., Tikoo, M., Powell, D. V. (2012, December). Instructor-Made Videos as a learner scaffolding tool. MERLOT Journal of Online Learning and Teaching, 8(1), 298-311. Retrieved from http://jolt.merlot.org/

Sadik, A. (2015). Students' preferences for types of video-lectures: Lecture capture vs. screencasting recordings. International Journal of Higher Education, 4(4), 94-104. doi:10.5430/ijhe.v4n4p94

Strauss, A., \& Corbin, J. (1998). Basics of qualitative research: Techniques and procedures for developing grounded theory. Thousand Oaks, CA: Sage Publications, Inc.

Sølvberg, A. M., \& Rismark, M. (2012). Learning spaces in mobile learning environments. Active learning in higher education, 13(1), 23-33. doi:10.1177/1469787411429189

Sølvberg, A. M., \& Rismark, M. (2016). Designing teaching practice in post-graduate education. Creative Education, 7(12), 1739-1748. doi:10.4236/ce.2016.712177

Tharp, R. G., \& Galimore, R. (2002). Rousing minds to life. doi:10.1017/cbo9781139173698 
Tondeur, J., Herman, F., De Buck, M., \& Triquet, K. (2017). Classroom biographies: Teaching and learning in evolving material landscapes (c. 1960-2015). European Journal of Education, 52(3), 280-294. doi:10.1111/ejed.12228

Tondeur, J., De Bruyne, E., Van Den Driessche, M., McKenney, S., \& Zandvliet, D. (2015). The physical placement of classroom technology and its influences on educational practices. Cambridge Journal of Education, 45(4), 537-556. doi:10.1080/0305764x.2014.998624

Verbeek, P. P. (2005). What things do? Philosophical reflections on technology, agency and design. University Park, PA: Pennsylvania State University Press.

Vygotsky, L. S. (1978). Mind in Society: The Development of Higher Psychological Processes. Cambridge, MA: Harvard University Press.

Wood, D. J., Bruner, J. S., \& Ross, G. (1976). The role of tutoring in problem solving. Journal of Child Psychology and Psychiatry, 17(2), 89-100. doi:10.1111/j.14697610.1976.tb00381.x 